\title{
Penile cancer: a local case series and literature review
}

\author{
Wei Da $\underline{L a u}^{1}$, MBBS, MMed, Chin Hu Ong${ }^{1}$, MBBS, FRCS, Tow Poh $\underline{\operatorname{Lim}}^{1}$, MBBS, FRCS, Colin $\underline{\operatorname{TeO}}{ }^{1}$, MBBS, FAMS
}

INTRODUCTION Penile cancer is an uncommon disease affecting only about one in 100,000 men worldwide in a year. The diagnosis of the condition is frequently delayed, and the disease and its treatment frequently result in significant morbidity in patients.

METHODS We herein describe seven cases of penile tumours: six cases of squamous cell carcinomas and one case of B-cell lymphoma that presented to our hospital's urology department between March 2011 and October 2012. We reviewed the literature to discuss the clinical presentation, natural history and current management of penile cancer. RESULTS The patients were followed up for 1-24 months. They were managed according to their disease stage and lymph node status. Four out of seven patients showed disease progression during the follow-up period.

CONCLUSION The accurate staging of inguinal nodes in cases of low-risk disease is important to prescribe appropriate surgery for the inguinal nodes. Aggressive management of inguinal and pelvic lymph nodes remains the cornerstone in the treatment of high-risk disease cases.

Keywords: penile cancer, penile lymphoma, penis, phimosis, squamous cell carcinoma

\section{INTRODUCTION}

Penile cancer is an uncommon disease affecting only about one in 100,000 men worldwide annually. ${ }^{(1)}$ While penile cancer often refers to squamous cell carcinomas (SCCs) of the penis in the literature, the term has also been used to describe nonsquamous penile malignant neoplasms. In this article, we describe seven cases of penile cancer that presented to our urology department over a period of 24 months, which were treated and followed up at our institution.

\section{CASE SERIES}

The hospital's admission and operating theatre records were searched for patients who were operated on or admitted for the diagnosis of penile cancer between March 2011 and October 2012. Their medical records were obtained from our Medical Records Office and data was analysed retrospectively. The demographics, presentation, treatment and subsequent outcome of the patients were reviewed and discussed (Tables I and II).

The review showed that seven men were diagnosed with penile cancer at our institution between March 2011 and October 2012. Their mean age was 63 (range 57-71) years. There were six Chinese patients and one Indian patient. Five of the seven patients were cigarette smokers. Three patients had phimosis at the point of diagnosis and all the patients were uncircumcised. One patient had concomitant human immunodeficiency virus infection. Two patients had a history of multiple sexual partners.

The average duration of the presenting complaint was 4.4 (range 0.5-12.0) months. The presenting complaints included bloody discharge from the penis (Fig. 1), penile swelling, penile redness, obstructive lower urinary tract symptoms and inguinal lumps. The tumour was located at the glans penis in five of the patients and the prepuce in one patient. Patient 6 presented with symptomatic anaemia and was found to have an effaced penis on physical examination (Fig. 2). All of the patients underwent

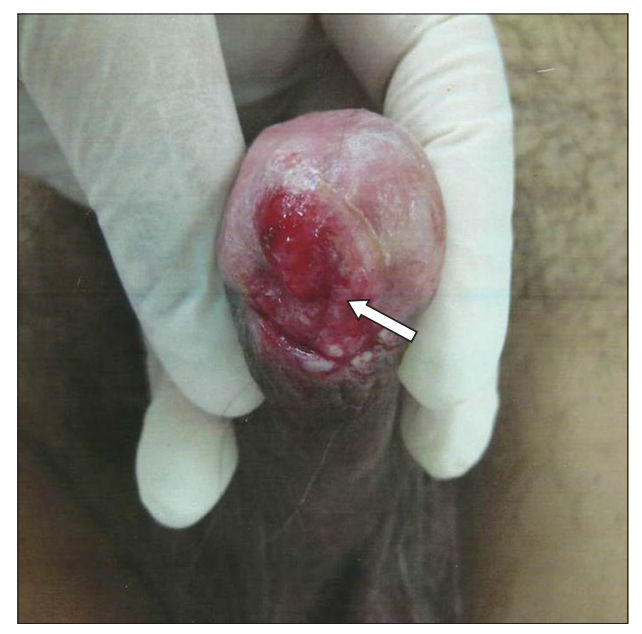

Fig. 1 Patient 1: Photograph shows effaced urethral meatus (arrow) that caused lower urinary tract symptoms.

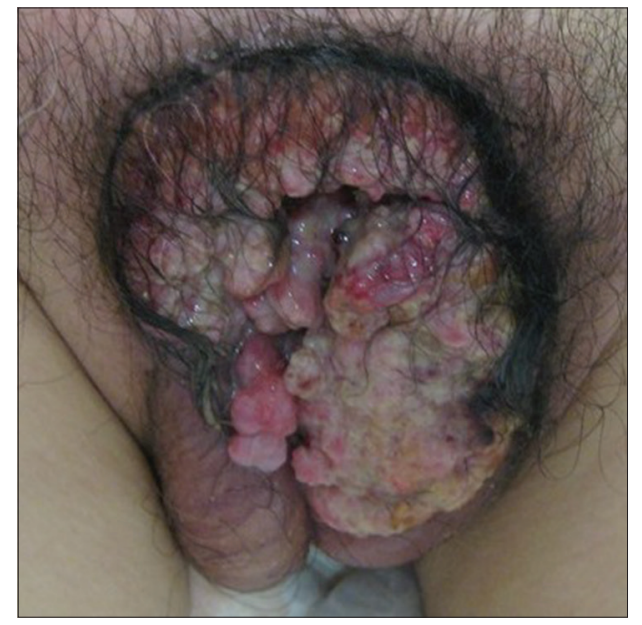

Fig. 2 Patient 6: Photograph shows an effaced penis.

incisional biopsy for histology. The pathology of the tumour was SCC in six of the patients and diffuse large B-cell lymphoma 
Table I. Demographics and presentation of the seven patients.

\begin{tabular}{|c|c|c|c|c|c|c|c|}
\hline Patient & 1 & 2 & 3 & 4 & 5 & 6 & 7 \\
\hline Age (yr) & 61 & 71 & 65 & 63 & 59 & 66 & 57 \\
\hline Race & Indian & Chinese & Chinese & Chinese & Chinese & Chinese & Chinese \\
\hline Cigarette smoking & Yes & Yes & No & Yes & No & Yes & Yes \\
\hline Multiple sex partners & No & No & No & No & Yes & Yes & No \\
\hline Foreskin status & Uncircumcised & Uncircumcised & Phimosis & Phimosis & Phimosis & Uncircumcised & Uncircumcised \\
\hline Comorbidity & Nil & DM, stroke & Hypertension & Nil & HIV & Nil & DM, IHD \\
\hline $\begin{array}{l}\text { Duration of penile } \\
\text { lump (mth) }\end{array}$ & 2.0 & 3.0 & 12.0 & 0.5 & 1.0 & 12.0 & 0.5 \\
\hline Presenting symptom & LUTS & $\begin{array}{l}\text { Penile } \\
\text { redness }\end{array}$ & $\begin{array}{l}\text { Itch, bloody } \\
\text { discharge }\end{array}$ & $\begin{array}{l}\text { Bloody discharge, } \\
\text { inguinal lump }\end{array}$ & $\begin{array}{l}\text { Swelling, bloody } \\
\text { discharge }\end{array}$ & $\begin{array}{l}\text { Symptomatic } \\
\text { anaemia }\end{array}$ & $\begin{array}{l}\text { Penile } \\
\text { swelling }\end{array}$ \\
\hline
\end{tabular}

DM: diabetes mellitus; HIV: human immunodeficiency virus; IHD: ischaemic heart disease; LUTS: lower urinary tract symptoms; NA: not applicable

Table II. Stages, treatments and outcomes of the seven patients.

\begin{tabular}{|c|c|c|c|c|c|c|c|}
\hline Patient & 1 & 2 & 3 & 4 & 5 & 6 & 7 \\
\hline Stage & $\begin{array}{l}\text { T1aNOM0 } \\
\text { (Stage I) }\end{array}$ & $\begin{array}{l}\text { T1aN0M0 } \\
\text { (Stage I) }\end{array}$ & $\begin{array}{l}\text { T1aN1M0 } \\
\text { (Stage IIIa) }\end{array}$ & $\begin{array}{l}\text { T3N1M0 } \\
\text { (Stage IIIa) }\end{array}$ & $\begin{array}{l}\text { T3N3M0 } \\
\text { (Stage IV) }\end{array}$ & $\begin{array}{l}\text { T4N3M0 } \\
\text { (Stage IV) }\end{array}$ & Ann Arbor I \\
\hline Histology & $\begin{array}{l}\text { Well } \\
\text { differentiated } \\
\text { SCC }\end{array}$ & $\begin{array}{l}\text { Moderately } \\
\text { differentiated } \\
\text { SCC }\end{array}$ & $\begin{array}{l}\text { Well } \\
\text { differentiated } \\
\text { SCC }\end{array}$ & $\begin{array}{l}\text { Poorly } \\
\text { differentiated } \\
\text { SCC }\end{array}$ & $\begin{array}{l}\text { Poorly } \\
\text { differentiated } \\
\text { SCC }\end{array}$ & $\begin{array}{l}\text { Poorly } \\
\text { differentiated } \\
\text { SCC }\end{array}$ & $\begin{array}{l}\text { Diffuse } \\
\text { large B-cell } \\
\text { lymphoma }\end{array}$ \\
\hline $\begin{array}{l}\text { Treatment for } \\
\text { primary tumour }\end{array}$ & Partial penectomy & $\begin{array}{l}\text { Partial } \\
\text { penectomy }\end{array}$ & $\begin{array}{l}\text { Partial } \\
\text { penectomy }\end{array}$ & $\begin{array}{l}\text { Total } \\
\text { penectomy }\end{array}$ & $\begin{array}{l}\text { Partial } \\
\text { penectomy }\end{array}$ & $\begin{array}{l}\text { Palliative } \\
\text { chemotherapy }\end{array}$ & $\begin{array}{l}\text { Primary } \\
\text { chemotherapy }\end{array}$ \\
\hline $\begin{array}{l}\text { Treatment for } \\
\text { lymph nodes }\end{array}$ & $\begin{array}{l}\text { Antibiotics, } \\
\text { surveillance, } \\
\text { delayed bilateral } \\
\text { LND on surveillance }\end{array}$ & Surveillance & $\begin{array}{l}\text { Excision } \\
\text { biopsy, then } \\
\text { unilateral } \\
\text { LND }\end{array}$ & $\begin{array}{l}\text { Unilateral } \\
\text { LND }\end{array}$ & $\begin{array}{l}\text { EBRT to } \\
\text { pelvic } L N\end{array}$ & $\begin{array}{l}\text { Palliative } \\
\text { chemotherapy }\end{array}$ & Nil LN \\
\hline Progression & Yes* & No & No & Yes $^{+}$ & Yes$^{\ddagger}$ & Yes $^{\S}$ & No \\
\hline $\begin{array}{l}\text { Time to } \\
\text { progression (mth) }\end{array}$ & 6 & NA & NA & 3 & 3 & 1 & NA \\
\hline Follow-up (mth) & 24 & 11 & 20 & 8 & 16 & 1 & 8 \\
\hline
\end{tabular}

${ }^{*}$ Recurrence at bilateral inguinal lymph nodes. †Distant metastasis. ${ }^{\ddagger} \mid$ ncomplete response to EBRT. $\S$ Death. EBRT: external beam radiation therapy; LN: lymph node; LND: lymph node dissection; NA: not applicable; SCC: squamous cell carcinoma

in Patient 7. Of the six cases of SCC tumours, two were well differentiated, one was moderately differentiated and three were poorly differentiated. Four of the six patients with SCCs underwent partial penectomy for the primary tumour, while Patient 4 underwent total penectomy. Three of the patients were at stage T1a, while another two patients were at stage T3 of the disease. Patient 6 had a locally advanced tumour and pelvic lymphadenopathy, and underwent palliative chemotherapy. Patient 7, who had diffuse large B-cell lymphoma, underwent primary chemotherapy. None of the patients with SCC had distant metastasis at the point of diagnosis.

Five of the six SCC cases had palpable inguinal lymphadenopathy at diagnosis. Only Patient 2 did not have any lymph node metastasis (i.e. stage $\mathrm{T} 1 \mathrm{G} 1 \mathrm{cN} 0$ ) and was put on surveillance with no disease progression at the seven-month follow-up. Patient 1 had palpable inguinal lymph node at diagnosis, which was initially resolved with six weeks of oral antibiotics. On surveillance at six months, he developed bilateral inguinal lymphadenopathy, for which he underwent delayed bilateral modified radical inguinal lymphadenectomy. Patients 3 and 4 had a unilateral mobile lymph node (i.e. N1 disease), for which they underwent unilateral modified radical inguinal lymph node dissection. Patient 5 had inguinal and pelvic lymphadenopathy, but decided against inguinal and pelvic lymphadenectomy, instead undergoing primary external beam radiation therapy on the pelvic lymph nodes.

The patients were followed up for 1-24 months. Patients 1 and 4 had significant disease progression during the follow-up period. Patient 1's cancer continued to progress after delayed lymphadenectomy. He developed tumour recurrence at the left inguinal region, and the left common and external iliac lymph nodes, for which he was referred for chemotherapy and radiotherapy. Patient 4 developed tumour recurrence at the base of the penis, bilateral inguinal lymph node metastasis and lung metastasis at the three-month follow-up (Fig. 3). He succumbed to wound sepsis six months after diagnosis. Patient 5 had stable pelvic lymph node metastasis. Patients 2, 3 and 7 remained tumour-free at follow-up.

\section{DISCUSSION}

Penile cancer is an uncommon malignancy that represents about $0.3 \%$ of all cancers in Singapore, based on records from the 

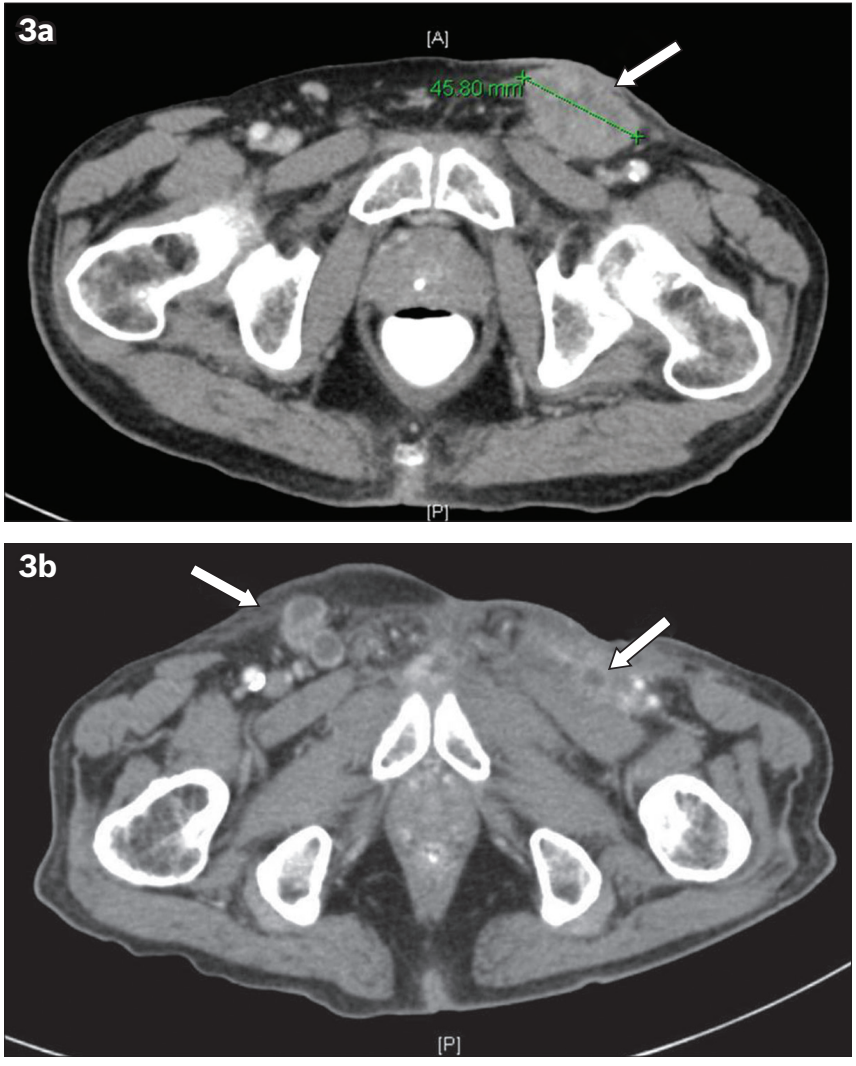

Fig. 3 Patient 4: (a) CT shows a $4.6 \mathrm{~cm}$ left inguinal lymph node metastasis (arrow). (b) Repeat CT at 10 weeks postoperative follow-up shows bilateral inguinal lymph node metastases (arrows).

Singapore Cancer Registry from 1968 to 1997. Penile cancer or penile carcinoma typically refers to SCC of the penis, although nonsquamous penile malignant neoplasms have been described in the literature.

Penile cancer, which occurs predominantly in elderly men (mean age at diagnosis 60 years), becomes more common with age, reaching a peak incidence at 70 years. ${ }^{(1)}$ Risk factors for penile cancer include human papilloma virus (HPV) infection, smoking, phimosis and poor hygiene, while neonatal circumcision has been described as protective. Up to $42 \%$ of penile carcinomas are HPV positive, and HPV infections are, in turn, directly related to the number of lifetime sexual partners. ${ }^{(1)}$ Penile cancer occurs almost exclusively in uncircumcised men, with a lifetime risk of one in 100,000 globally, compared to 0.1 in 100,000 in Israel, where the majority of men are circumcised. ${ }^{(2)}$ Circumcision prevents conditions such as phimosis, retention of smegma and lichen sclerosus, and decreases the risk of HPV infections. All the patients in our case series were uncircumcised and three of them had phimosis. The presence of phimosis allows the buildup of smegma, which results in chronic irritation and inflammation of the glans and prepuce. It is likely that phimosis also contributes to the delayed diagnosis of penile cancer. Tobacco use, including cigarette smoking, is also strongly associated with an increased risk of penile cancer, although its exact role remains unclear.

The delay in diagnosis of penile cancer has been well documented. In our case series, the mean delay in seeking treatment was 4.4 months. The reasons for delay include embarrassment, guilt, fear, ignorance and personal neglect. The initial tumour often begins at the glans penis or in the prepuce and gradually extends to involve the entire glans, shaft and corpora. The lesion may present as an induration, a painless nodule, a wartlike growth, an ulceration, or an exophytic lesion. Subsequently, as the prepuce erodes, a foul odour and discharge from the lesion may occur. In our series, most of the patients ignored the initial penile lump and delayed seeking treatment until problems of bloody discharge, obstructive urinary symptoms and symptomatic anaemia occurred.

The regional femoral and iliac lymph nodes are the sites of penile carcinoma lymphatic metastasis. The lymphatics from the prepuce join the lymphatics from the skin of the shaft and drain into the superficial inguinal nodes. The lymphatics of the glans join the lymphatics draining the corpus cavernosum and spongiosum, forming a collar of connecting channels at the base of the penis that also drains into the superficial inguinal nodes. The superficial nodes drain into the deep inguinal nodes, which then drain into the pelvic nodes. Penile carcinoma can metastasise to the lung, bone and liver. However, distant metastases occur late in the course of the disease, usually in patients with significant inguinal and pelvic lymphadenopathy. ${ }^{(3)}$

We staged the penile squamous cell carcinomas according to the seventh edition of the American Joint Committee on Cancer TNM Cancer Staging Manual. ${ }^{(4)}$ Accurate staging of the primary lesion is important in making treatment decisions and prognosticates the risk of associated lymph node metastases. Physical examination has been shown to be accurate in determining the likelihood of corpus cavernosum invasion, in comparison to penile ultrasonography and magnetic resonance (MR) imaging. ${ }^{(5)}$ Artificial erection with contrast-enhanced MR imaging may be useful in situations where accurate T-staging is required prior to planning for organ-sparing therapy. ${ }^{(6)}$ However, surgical amputation of the primary tumour remains the oncologic gold standard for definitive treatment of penile tumours. Organsparing or glans-sparing procedures can be considered for early stage Tis, Ta and T1 tumours with good histology (i.e. Grades 1 or 2). These techniques include limited excision with or without circumcision, Mohs micrographic surgery, laser ablation and radiotherapy, with the aim of preservation of penile length and sensation. In our case series, the patients were not amenable to limited excision and our experience with the other techniques was limited, so contemporary penile amputation was performed in all SCC cases.

The presence and extent of inguinal lymph node metastases are the most important prognostic factors for survival in patients with penile SCCs. At initial presentation, clinically palpable lymph nodes are present in $28 \%-64 \%$ of patients, $47 \%-85 \%$ of lymphadenopathies are caused by metastatic invasion and the rest are due to inflammatory reactions. $12 \%-20 \%$ of patients without palpable inguinal lymph nodes harbour cancerous occult tumours. ${ }^{(7)}$ The case for early inguinal lymphadenectomy has to be justified against the significant morbidity of the procedure. The complications of inguinal lymphadenectomy include phlebitis, pulmonary embolism, wound infection, flap necrosis, and permanent and disabling lymphoedema of the scrotum and lower 
limbs. There is increasing evidence that early inguinal lymph node dissection confers a better prognosis compared to surveillance and delayed inguinal dissection. ${ }^{(8)}$ In our series, the patients whose cancers progressed appeared to have been undertreated for their lymph node metastasis.

In patients with palpable inguinal lymph nodes, fine-needle aspiration cytology (FNAC) is currently recommended at the time of, or immediately after, treatment of the primary tumour. A core biopsy or excisional biopsy can also be performed. In cases with a negative FNAC finding, the following strategies are acceptable: (a) 4-6 weeks of antibiotics; (b) repeat FNAC; (c) excision biopsy of the lymph nodes; and (d) inguinal lymphadenectomy..${ }^{(9)}$ In our series, Patient 1, a case of palpable inguinal lymph node with negative FNAC, was treated with six weeks of antibiotic therapy for the initial resolution of lymphadenopathy. He developed disease progression with clinical inguinal lymph node metastasis at the six-month follow-up. Despite delayed inguinal lymph node dissection, the patient's cancer progressed to pelvic lymph node metastasis. Given the high risk of lymph node metastasis in patients with palpable inguinal lymph nodes and the benefits of early inguinal dissection compared to a delayed procedure, his disease progression could have been prevented by an attempt to stage his lymph node status accurately via excision biopsy or inguinal lymphadenectomy.

In addition, in cases of high-risk disease (T1G3, T2-T4) such as Patient 4, aggressive management of lymph node metastasis is indicated. Patient 4 had a unilateral positive mobile inguinal node, for which an ipsilateral inguinal superficial and deep lymph node dissection and pelvic node dissection with a contralateral superficial inguinal dissection has been advocated. ${ }^{(3,9)}$ Such an approach may have prevented an early inguinal and pelvic lymph node recurrence and subsequent distant metastases. Radiation to inguinal nodes is not as effective as surgery, and primary radiation to pelvic lymph nodes (i.e. N3 disease) is not well established. ${ }^{(3,9}$

For patients without palpable lymph nodes, a risk-stratified approach can be used to decide on further management of the inguinal region. Very low-, low- and intermediate-risk patients with stage Tis, Ta, T1G1-2 cancer can be put under observation, while high-risk patients with stage T2-T4 cancer or vascular invasion or nodular growth pattern on histology should be offered bilateral superficial inguinal dissection with frozen section, or complete modified dissection. ${ }^{(3)}$ Recent studies have found that dynamic sentinel node biopsy, especially when combined with ultrasonography with or without FNAC, provides high sensitivity in the detection of inguinal metastasis in clinically NO cases, with a lower morbidity rate compared to inguinal lymph node dissection. ${ }^{(10)}$

Chemotherapy may be offered in an adjuvant setting, for N2 disease after complete surgical treatment of the local disease and inguinal lymph node metastasis. Combination chemotherapy containing cisplatin has been suggested as a form of neoadjuvant therapy for patients with palpable lymph nodes, especially large, immobile inguinal nodal metastasis. In patients with stable or responsive diseases after neoadjuvant chemotherapy, surgical consolidation can be considered. Advanced penile cancer refers to cases that meet the following criteria: (a) unresectable primary tumour (i.e. T4 disease); (b) fixed, bulky or relapsed inguinal lymph nodes; and (c) cases with visceral metastasis. The results of chemotherapy in advanced penile cancer are poor, with a minimal chance of curative treatment. ${ }^{(11)}$

Primary lymphoreticular malignant neoplasms of the penis are rare. Based on a recent review of the literature, there have been about 50 reported cases of primary penile lymphoma to date. ${ }^{(12)}$ Diffuse large B-cell lymphoma was the most frequent subtype in 14 out of 38 available cases with pathological results. Systemic chemotherapy is considered first-line treatment to achieve total alleviation and preservation of penile function and shape, as well as treatment of potential systemic disease. Local low-dose radiation therapy has also been reported to be successful.

\section{CONCLUSION}

Penile cancer continues to be a devastating disease; the patient often presents late and the primary tumour is commonly treated by a disfiguring penile amputation. Accurate staging and appropriate management of the inguinal lymph nodes remain a challenge that has important prognostic implications. A risk-stratified approach has been advocated. Our case series has shown that the accurate staging of inguinal nodes in cases of low-risk disease is important to prescribe appropriate surgery for the inguinal nodes, and that aggressive management of inguinal and pelvic lymph nodes remains the cornerstone in the treatment of high-risk disease cases.

\section{REFERENCES}

1. Bleeker MC, Heideman DA, Snijders PJ, et al. Penile cancer: epidemiology, pathogenesis and prevention. World J Urol 2009; 27:141-50.

2. Morris BJ, Gray RH, Castellsague X, et al. The strong protective effect of circumcision against cancer of the penis. Adv Urol 2011; 2011:812368.

3. Pettaway CA, Lance RS, Davis JW. Tumors of the penis. In: Wein AJ, Kavoussi LR, Novick AC, Partin AW, Peters CA. Campbell-Walsh Urology. 10th ed. Philadelphia: Elsevier Health Sciences, 2011: 901-33.

4. Edge SB, Byrd DR, Compton CC, et al, eds. AJCC Cancer Staging Manual (7th edition). France: Springer, 2010.

5. Lont AP, Besnard AP, Gallee MP, van Tinteren H, Horenblas S. A comparison of physical examination and imaging in determining the extent of primary penile carcinoma. BJU Int 2003; 91:493-5.

6. Scardino E, Villa G, Bonomo G, et al. Magnetic resonance imaging combined with artificial erection for local staging of penile cancer. Urology 2004; 63:1158-62.

7. Heyns CF, Mendoza-Valdés A, Pompeo AC. Diagnosis and staging of penile cancer. Urology 2010; 76(2 Suppl 1):S15-23.

8. McDougal WS. Carcinoma of the penis: improved survival by early regional lymphadenectomy based on the histological grade and depth of invasion of the primary lesion. J Urol 1995; 154:1364-6.

9. Pizzocaro G, Algaba F, Horenblas S, et al; European Association of Urology (EAU) Guidelines Group of Penile Cancer. EAU penile cancer guidelines 2009. Eur Urol 2010; 57:1002-12.

10. Lam W, Alnajjar HM, La-Touche S, et al. Dynamic sentinel lymph node biopsy in patients with invasive squamous cell carcinoma of the penis: a prospective study of the long-term outcome of 500 inguinal basins assessed at a single institution. Eur Urol 2013; 63:657-63.

11. Hakenberg OW, Protzel C. Chemotherapy in penile cancer. Ther Adv Urol 2012; 4:133-8.

12. Chu L, Mao W, Curran Vikramsingh K, et al. Primary malignant lymphoma of the glans penis: a rare case report and review of the literature. Asian J Androl 2013; 15:571-2. 